\title{
MANUAL DE REVISÃO: UM GUIA PARA O TRABALHO DO REVISOR DE TEXTO
}

\author{
Gisele Dalmolin Bonella ${ }^{1}$; Valeria lensen Bortoluzzi ${ }^{2}$
}

\section{RESUMO}

O trabalho do revisor de texto oferece muitos desafios. São vários os aspectos que o revisor precisa corrigir em um texto. Porém, muitas vezes o revisor sente a necessidade de uma fonte para sanar dúvidas rotineiras em relação ao seu trabalho. Assim, nosso principal objetivo é de proporcionar um material de apoio aos revisores de texto e estudantes de Letras. Os métodos utilizados foram: estudo teórico dos conteúdos a serem disponibilizados no manual; confecção do manual; compartilhamento do manual e do formulário de avaliação, com revisoras de texto que participaram da validação do material. Como principais resultados e conclusões obtidos, percebemos que o Manual de Revisão oferece uma boa fonte aos revisores, mas o material precisa ser ampliado para que possa ajudar mais profissionais do texto.

Palavras-chave: Textual; Gramática; Correção.

Eixo Temático: Educação, Cultura e Comunicação.

\section{INTRODUÇÃO}

Encontramos o trabalho do revisor de texto em diversos lugares e contextos. $\mathrm{Na}$ escola, esse trabalho é comumente chamado de 'correção' e é feito pelo(a) docente de Língua Portuguesa quando avalia a produção textual de seus alunos. $\mathrm{Na}$ universidade, o trabalho de revisão textual é procurado pelos acadêmicos quando é chegada a hora da publicação de artigos, resumos e ensaios. Pessoas com formação em Letras e Jornalismo são as mais indicadas para oferecer esse serviço,

\footnotetext{
${ }^{1}$ Universidade Franciscana - g.bonella@ufn.edu.br.

${ }^{2}$ Universidade Franciscana - valbortoluzzi@ufn.edu.br.
} 
mas também vemos revisores com as mais variadas formações, que trabalham com o texto por terem um conhecimento maior acerca da nossa língua.

\subsection{A REVISÃO DE TEXTO}

Mas, afinal, o que é a revisão de texto? De acordo com Brandão (2007, p. 120), "revisar um texto é torná-lo objeto de nossa reflexão, é pensar sobre o que foi ou está sendo escrito e encontrar meios para melhor dizer o que se quer dizer, reelaborando e reescrevendo o já escrito". Podemos pensar, com essa fala, que se trata de um trabalho simples, em que apenas lemos e refletimos sobre o texto, mas o trabalho de revisão envolve vários aspectos.

O trabalho do revisor carrega complexidade: além de questões pontuais, como ortografia, concordância verbal e uso de letras maiúsculas e minúsculas, o revisor deve prestar atenção a questões mais gerais do texto, como o gênero textual, a articulação das ideias, enfim, a organização do texto.

\subsection{O TRABALHO DO REVISOR E SEUS DESAFIOS}

Moraes (2020) ressalta a importância do trabalho do revisor de texto não só em relação às suas atribuições, mas também em relação à revisão que ele faz de todo o trabalho que envolve a edição de um livro.

Do autor, o revisor deve observar o estilo, a obediência à norma (as várias que hoje há, além da padrão) e a coerência do texto; dos editores, o projeto do livro, a organização dos capítulos, os títulos e o padrão da editora; do tipógrafo e do diagramador, o respeito à tipologia escolhida pelo projeto gráfico; e assim por diante (MORAES, 2020, p. 22).

Assim, o autor nos explica que o revisor não tem o papel apenas de corrigir a gramática e os erros tipográficos. Em razão do trabalho do revisor ser um dos últimos entre os vários processos de uma produção, etapas como conferência de títulos e obediência às normas também são trabalho do revisor (MORAES, 2020). 
Para demonstrar que o revisor não trabalha apenas com a correção de alguns usos linguísticos, Coelho e Antunes (2010) explicam que a revisão não se resume a apenas uma vertente. Na figura 1.1, podemos ver quatro tipos de revisão apresentados pelas autoras.

Figura 1.1 - Tipos de revisão

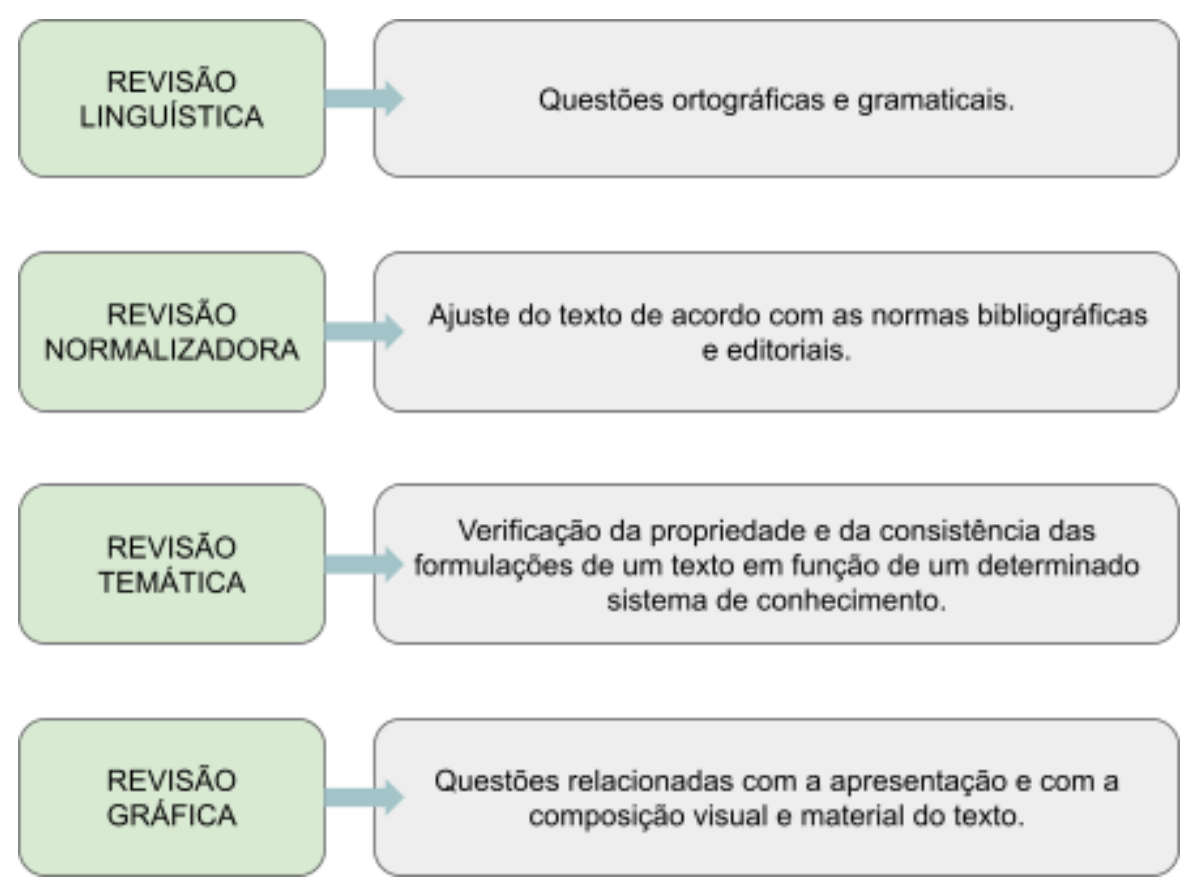

Fonte: elaborado pela autora com base em Coelho e Antunes (2010).

A figura 1.1 nos mostra quatro tipos de revisão. O primeiro deles, a revisão linguística, é provavelmente o mais conhecido, tanto entre os estudantes da área quanto entre as pessoas que contratam esse tipo de serviço. O segundo tipo poderia ser comparado ao que muitos chamam de 'formatação'. Já a revisão temática se refere à consistência das informações e a situação em que o texto se encontra. A última revisão, a gráfica, cuida de questões relacionadas aos aspectos gráficos do texto.

Ao pensarmos em todos esses pontos referentes à revisão, fica claro que o revisor precisa estar sempre se atualizando em seu trabalho devido às várias demandas pelas quais é responsável. Além disso, o revisor de texto enfrenta diversos desafios em sua jornada de trabalho, entre eles está a falta de fontes 
seguras para a pesquisa que eventualmente precisa fazer em sua rotina de trabalho com o texto.

Com o grande número de informações que encontramos na internet, não é difícil nos depararmos com sites que não tiveram a base teórica adequada na produção de seus conteúdos e, por isso, não oferecem material com a qualidade buscada por um revisor de texto. Muitas vezes, a mesma informação é somente reproduzida em diversos locais da rede, sem a preocupação do autor em relação à fonte do texto que está compartilhando com o seu público.

Por isso, nossa proposta é criar um material para estudantes de Letras interessados em seguir a carreira de revisão de texto e revisores que já atuam nesse meio. O Manual de Revisão foi criado para ser compartilhado de maneira digital na ferramenta Canva. Assim, nosso principal objetivo é de proporcionar um material de apoio aos revisores de texto e estudantes de Letras. Para isso, iremos abordar técnicas de revisão, sanar algumas dúvidas relacionadas à rotina de trabalho do revisor e promover a cooperação entre revisores de texto em relação aos seus trabalhos.

Os manuais são de grande valia para que possamos acessar uma informação de forma rápida e prática. De acordo com o Dicionário Michaelis On-line (2021), 'manual' pode ser definido como:

1 Livro pequeno que contém noções básicas relativas a uma disciplina ou de uma técnica.

2 Livro que oferece orientação para a execução ou o aperfeiçoamento de determinada atividade; guia prático.

Desse modo, podemos perceber que o manual serve como um guia com noções práticas sobre algum assunto, que oferece orientações para desempenhar alguma função ou aperfeiçoar alguma atividade. Essas definições vão de encontro a nossa proposta, pois a intenção é de ajudar os revisores a terem um material prático em mãos nos momentos em que precisam sanar alguma dúvida.

Nesse sentido, chamamos a atenção para duas expressões usadas nas 
definições de manual: "noções básicas" e "aperfeiçoamento de determinada atividade". As duas expressões resumem a intenção deste projeto, que é de criar um manual com tópicos básicos de português, para que o revisor possa aperfeiçoar os conhecimentos que já possui sobre a língua.

Esses conhecimentos que o revisor adquire antes de trabalhar com a revisão podem ser desenvolvidos com o uso de uma gramática. Uma boa gramática deve sempre ser a principal fonte do revisor, pois trata-se do livro que apresenta as regras e normas de uso de uma língua. Portanto, nossa proposta também terá a gramática como base, mais especificamente, a Moderna Gramática Portuguesa (2019), de Evanildo Bechara, e a Novíssima Gramática da Língua Portuguesa (1996), de Domingos Paschoal Cegalla.

\section{METODOLOGIA}

O presente trabalho realizou-se por meio de duas etapas: confecção do Manual de Revisão e validação do Manual de Revisão. Para validarmos o material, o manual foi disponibilizado a três colegas revisoras, que trabalham com a revisão de textos tanto com vínculo empregatício quanto como freelancers. Ao seguirmos esses passos, a ideia inicial era de que as revisoras que fizessem a leitura do material pudessem dar sugestões de melhoria de acordo com o que vivenciam em suas rotinas de trabalho.

Cada colega convidada a participar da validação respondeu às perguntas e comandos abaixo, que foram disponibilizados por meio de um formulário feito no site Google Forms.

1) Você acha que materiais como o manual de revisão são importantes para os profissionais do texto?

2) Marque, entre as opções abaixo, qual(is) parte(s) do protótipo do manual de revisão que, na sua opinião, precisam ser complementadas com mais informações. 
EDUCAÇÃO, SAÚDE

ETECNOLOGIA

26 A 28 DE OUTUBRO DE 2021

3) O material oferece boas fontes para consulta?

4) As questões apontadas no manual são relevantes para o seu trabalho de revisão?

5) Você já teve dúvidas a respeito de alguma das dificuldades citadas na seção "Dificuldades da língua portuguesa"?

6) Você tem sugestões para melhorar o material? Quais?

Portanto, de forma resumida, o material produzido foi elaborado a partir das seguintes etapas:

- estudo teórico dos conteúdos a serem disponibilizados no manual;

- confecção do manual;

- compartilhamento do manual e do formulário de avaliação com as revisoras que participaram da validação do material.

\section{RESULTADOS E DISCUSSÕES}

Os resultados obtidos referem-se ao material proposto, o Manual de Revisão, e às respostas das revisoras que participaram da validação do material. $O$ conhecimento que foi desenvolvido no manual se refere a noções de gramática da língua portuguesa. Além disso, o manual contém alguns conceitos, classificações e dicas acerca do trabalho do revisor de texto. Também, no decorrer do manual, disponibilizamos links úteis ao trabalho do revisor. A figura a seguir apresenta o sumário do manual.

Figura 1.2 - Sumário do Manual de Revisão 

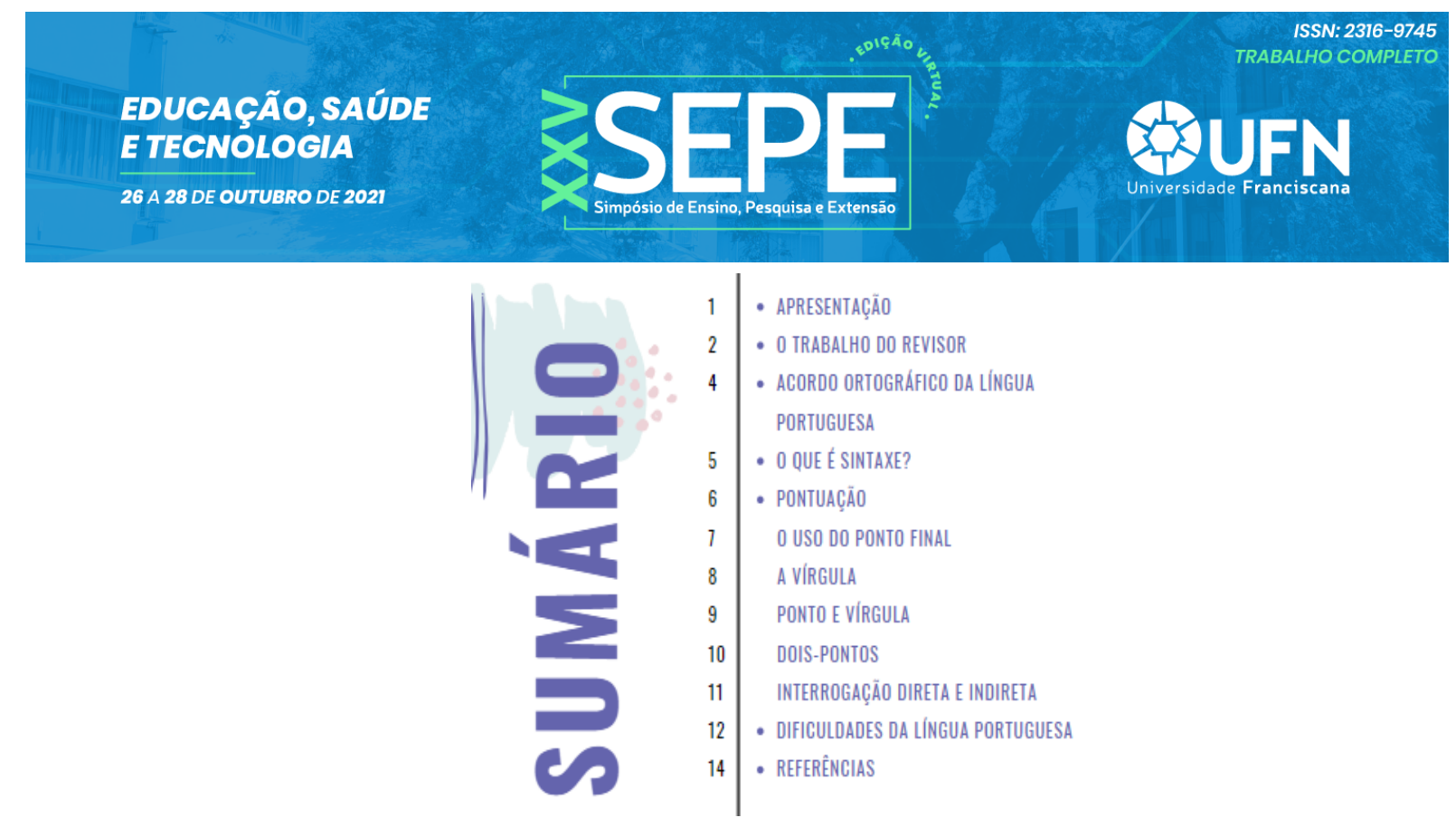

Fonte: Canva.

Como podemos ver, o manual é dividido em cinco partes, além das subdivisões do item "Pontuação", da apresentação e das referências. A seguir, detalhamos cada capítulo do manual.

1. O trabalho do revisor: na primeira página sobre o trabalho do revisor, explicamos, como o título já diz, o trabalho do revisor de texto. Ao final da página, é apresentado um esquema com os itens que devem receber a atenção do revisor em qualquer texto, tais como: pontuação, parágrafos, gênero textual, recursos coesivos, organização das ideias, ambiguidades, entre outros. Na próxima página, trazemos um citação de Moraes (2020), que fala sobre o trabalho complexo do revisor. O autor explica que o revisor de texto deve observar todo o trabalho que envolve a edição de um livro (caso trabalhe em uma editora), como a organização dos capítulos, o padrão do diagramador e o projeto gráfico. Portanto, fica claro que o revisor de texto não corrige somente a ortografia, mas deve ter uma visão geral do texto que está revisando.

2. Acordo ortográfico da língua portuguesa: nesta seção bem breve, fizemos uma pequena apresentação sobre o último acordo ortográfico da língua portuguesa, que entrou em vigor no Brasil em 2009. Além disso, indicamos alguns links úteis acerca desse assunto: o primeiro direciona ao Acordo, o 
segundo é o link do VOLP (Vocabulário Ortográfico da Língua Portuguesa), e os dois últimos são dos dicionários on-line Michaelis e Aulete, que já estão atualizados com o novo acordo.

3. O que é sintaxe?: aqui, temos uma breve conceituação sobre a sintaxe, de acordo com Sautchuk (2010). Depois, apresentamos uma figura que explica quais são os objetos de estudo da sintaxe. A seguir, ilustramos também o conceito de morfologia, já que nas gramáticas mais modernas utiliza-se o termo morfossintaxe, que se refere à união desses dois estudos. E, por último, disponibilizamos o link de um vídeo do professor Pasquale Cipro Neto sobre análise sintática.

4. Pontuação: a seção de pontuação foi a etapa mais desenvolvida no manual. Optamos por dar destaque à pontuação por ser um dos aspectos que mais corrigimos em textos de diferentes gêneros, principalmente quando se trata da vírgula. Nesta primeira página sobre pontuação, há uma definição de Bechara (2019), que diz que os sinais de pontuação ajudam os enunciados a exercerem sua função comunicativa. As próximas páginas do manual sintetizam alguns sinais de pontuação, que estão listados a seguir.

4.1 O uso do ponto final: sobre o ponto final, buscamos trazer um exemplo antes do conceito, para que fosse possível visualizar como esse sinal é utilizado. O exemplo trazido é sobre o uso do ponto na abreviação "etc." em um artigo acadêmico. Depois do exemplo, colocamos o conceito de ponto final de acordo com Bechara (2019).

4.2 A vírgula: na parte que explica os usos da vírgula, apresentamos apenas alguns casos em que esse sinal é utilizado. Os exemplos foram retirados de um livro sobre produção textual.

4.3 Ponto e vírgula: nesta página, excertos de um artigo serviram de exemplo para explicar os usos do ponto e vírgula. Ao final da página, disponibilizamos o link da "Gramática básica do português contemporâneo".

4.4 Dois-pontos: é feita uma relação entre o uso de dois-pontos em um título 


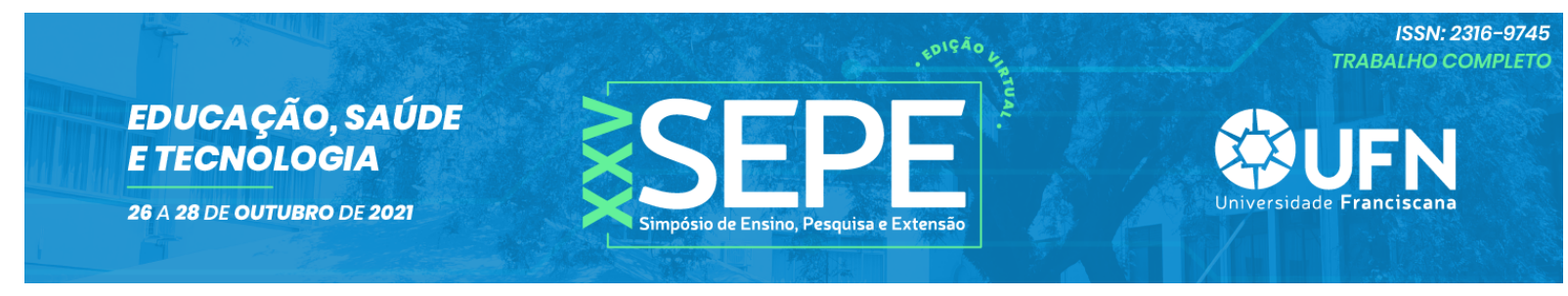

de notícia e uma listagem de itens em um artigo acadêmico. Utilizamos a notícia pois, segundo Bechara, é um dos gêneros textuais que mais usa os dois-pontos para resumir certas notícias.

4.5 Interrogação direta e indireta: no último sinal de pontuação apresentado, também utilizamos como exemplo um título de notícia, e explicamos a diferença entre interrogação direta e indireta. Esses dois tipos de interrogação ainda são itens que o revisor por vezes tem que corrigir em diversos textos.

5. Dificuldades da língua portuguesa: essa é a última parte do manual. Trouxemos apenas algumas dificuldades, de maneira bastante pontual. $\mathrm{Na}$ última página de conteúdo, novamente sugerimos links úteis em relação ao assunto do capítulo.

Como explicado anteriormente, duas revisoras de texto que trabalham no setor de educação a distância da Universidade Franciscana (Santa Maria, RS) foram responsáveis por testar e validar o Manual de Revisão. Ambas responderam a um questionário on-line, disponibilizado pela plataforma Google Forms. A seguir, iremos detalhar as respostas do formulário de validação.

Para começar, as respostas das revisoras para a primeira pergunta do formulário foram favoráveis ao Manual de Revisão. De acordo com as duas revisoras que participaram da validação, materiais como o manual de revisão são importantes para os profissionais do texto.

Na questão 2, foi pedido às revisoras que marcassem qual parte ou seção do manual precisa de mais informações. Uma das revisoras marcou a última opção, que indica que o material não precisa de mais informações, ou seja, a revisora considera que o manual de revisão está completo. A segunda revisora marcou que a seção "Dificuldades da língua portuguesa" precisa de complementos. Na última questão, que pergunta sobre sugestões para melhorar o trabalho, a revisora especifica quais informações devem ser adicionadas nessa parte do manual. 
Nas questões 3 e 4, é perguntado se o material oferece boas fontes para consulta e se as questões apresentadas no manual são relevantes para o trabalho de revisão. Ambas as revisoras responderam que sim às duas questões.

Na questão 5, podemos perceber que ambas as revisoras já tiveram dúvidas a respeito de alguns tópicos apresentados na seção "Dificuldades da língua portuguesa". Essa pergunta foi feita especificamente sobre essa seção pois é a parte que mais pode ser ampliada, já que a lista de dificuldades da nossa língua é bastante extensa e variada.

A última questão mostra que as revisoras aprovaram o material. Apenas uma delas deu sugestões acerca do capítulo "Dificuldades da língua portuguesa". São sugestões bastante válidas, pois a crase é um assunto que gera dúvidas e é bastante corrigido pelos revisores. A diferença entre "esta" e "está" foi sugerida talvez por ser um item já corrigido inúmeras vezes pela revisora, e acredito que poderia ser complementado com a diferença entre "isto" e "isso", "esse" e "este", entre outros tópicos.

\section{CONCLUSÃO}

Portanto, o presente trabalho surgiu da necessidade de haver um material desenvolvido especialmente para os revisores de texto, focado na rotina de trabalho desses profissionais e nas dúvidas que surgem no decorrer da revisão. Desse modo, o nosso intuito é de compartilhar com estudantes de Letras e revisores um material que tenha como fontes gramáticas e dicionários confiáveis, para que seja feito um trabalho de revisão com mais confiança. Além disso, muitos revisores freelancers dividem sua jornada de trabalho de revisor com outros afazeres e/ou trabalho com vínculo empregatício, por isso a praticidade na hora da busca de informações em um momento de dúvida também é importante. 
Após a validação por meio das respostas de revisoras de texto, que trabalham diariamente nesse ofício ou fazem revisão textual à parte de seu vínculo empregatício, esperamos que seja atingido o objetivo de proporcionar um material de apoio aos revisores de texto e estudantes de Letras. Também, o intuito é de que as revisoras consigam perceber suas fraquezas e potencialidades, para que possam sempre aprimorar e estudar a língua.

Mas, a ideia é que o trabalho possa ser aprimorado e ampliado no futuro. Pretendemos escrever mais sobre o trabalho do revisor e dar dicas para revisores que estejam começando o trabalho ou para estudantes de Letras que estejam interessados em seguir essa carreira. Também, a parte sobre a sintaxe poderia tornar-se mais completa, com exemplos e definições sobre a análise sintática. Além disso, seria interessante indicar os tipos de revisão textual. A parte de dificuldades de língua portuguesa também poderia ser bastante ampliada.

\section{REFERÊNCIAS}

BECHARA, E. Moderna gramática portuguesa. 39. ed., rev. e ampl. Rio de Janeiro: Nova Fronteira, 2019.

BRANDÃO, A. C. P. A revisão textual na sala de aula: reflexões e possibilidades de ensino. In: LEAL, T. F.; BRANDÃO, A. C. P. (org.). Produção de textos na escola: reflexões e práticas no ensino fundamental. Belo Horizonte: Autêntica, p. 119-134, 2007.

CEGALLA, D. P. Novíssima gramática da língua portuguesa. 39. ed. São Paulo, SP: Nacional, 1996. 587 p. 
COELHO, S. M.; ANTUNES, L. B. Revisão textual: para além da revisão linguística. SCRIPTA, Belo Horizonte, v. 14, n. 26, p. 205-224, jan./jun. 2010. Disponível em: <http://periodicos.pucminas.br/index.php/scripta/article/view/4361/4506>. Acesso em: 05 jun. 2021.

MANUAL. In: Michaelis. Editora Melhoramentos Ltda., 2021. Disponível em: <https://michaelis.uol.com.br/palavra/dNXa4/manual-2/>. Acesso em: 23 jun. 2021.

MORAES, E. V. de. Processos de revisão textual [livro eletrônico]. Curitiba: InterSaberes, 2020. 